Çukurova Üniversitesi Mühendislik Mimarlık Fakültesi Dergisi, 31(ÖS 1), ss. ÖS 1-ÖS 9, Ağustos 2016

Çukurova University Journal of the Faculty of Engineering and Architecture, 31(ÖS 1), pp. SI 1- SI 9, August 2016

\title{
API 5L X65 Çeliklerinin MAG Kaynak Yöntemi ile Birleştirilmesinde, Kaynak İşleminin Mikroyapı ve Mekanik Özelliklere Etkisinin İncelenmesi
}

\author{
Hakan ADA ${ }^{* 1}$, Sinan AKSÖZ ${ }^{1}$, Tayfun FINDIK ${ }^{2}$ \\ Cemil ÇETINKAYA ${ }^{2}$, Bülent BOSTAN ${ }^{2}$, İlhan CANDAN ${ }^{3}$ \\ ${ }^{1}$ Gazi Üniversitesi, Teknik Bilimler MYO, Makine ve Metal Teknolojisi Bölümü, Ankara \\ ${ }^{2}$ Gazi Üniversitesi, Teknoloji Fakültesi, Metalurji ve Malzeme Mühendisliği Bölümü, Ankara \\ ${ }^{3}$ Emek Boru Mak. San. ve Tic. A.Ş, Ankara
}

Geliş tarihi: 14.10.2015 Kabul tarihi: 30.04 .2016

\section{Özet}

Bu çalışmada; doğalgaz ve petrol boru hatlarında kullanılan API 5L X65 kalitesindeki çelik malzemeler, MAG kaynak yöntemiyle özlü rutil tel ile birleştirilmiştir. Birleştirmelerden alınan numunelerin mikroyapı ve mekanik özelliklere etkileri incelenmiştir. Deneysel çalışmalarda makro ve mikroyapısal olarak, ana malzeme, ITAB) ve kaynak metali incelenmiş, oluşan yapıların tipik kaynak işlem özelliklerine sahip yapılar olduğu tespit edilmiştir. Çekme, çentik darbe, sertlik ve eğme testlerinde kaynak işlemi kusursuz özellikler sergilemiştir. Elde edilen tüm sonuçlar, kaynak işleminin mikroyapısal ve mekanik olarak kendinden beklenen lokal özellikleri karşılayabilecek bir tavır sergilediğini göstermiştir.

Anahtar Kelimeler: Kaynak, Çelik boru, MAG Kaynağı, Kaynak teli

\section{The Investigation of Effect of Welding Process on The Microstructure and Mechanical Properties of API 5L X65 Steel Welded with Gas Metal Arc Welding Method}

\begin{abstract}
In this study, API 5L X65 steel pipes, used in natural gas and oil pipelines, was welded by the FCAW method using rutile flux-cored wire electrodes. The microstructure and mechanical properties of the samples were investigated. In the experimental studies, the microstructure of main material, HAZ and FZ was examined. It was determined that the formed structures were typical characteristic structures for medduring welding process. Welding process demonstrated perfect features in tensile, charpy impact, hardness and guided bend tests. All results obtained from experimental studies have showed that the welding process exhibits expected local properties as microstructural and mechanical.
\end{abstract}

Keywords: Welding, Steel pipe, Gas metal arc welding, Welding wire

\footnotetext{
* Sorumlu yazar (Corresponding author): Hakan ADA, Gazi Üniversitesi Teknik Bilimler Meslek Yüksekokulu, Makine ve Metal Teknolojisi Bölümü, Ankara, hakanada@gazi.edu.tr
} 
API 5L X65 Çeliklerinin MAG Kaynak Yöntemi ile Birleştirilmesinde, Kaynak Işsleminin Mikroyapı ve Mekanik Özelliklere Etkisinin Incelenmesi

\section{GIiRIŞ}

Boru hatt1 sistemleri; gaz, petrol ya da buhar gibi akışkan ürünlerin güvenli bir şekilde taşınması işlemlerinde büyük ölçüde kullanılmaktadır. Doğalgaz ve petrol taşımacılığında kullanılan boru hatları; toprak kayması, göçük gibi dış kuvvetlerin sebep olduğu plastik deformasyona maruz kalabilir. $\mathrm{Bu}$ nedenle boru hattı malzemesi ve bağlantı sistemlerinin, dişarıdan gelebilecek olumsuz etkilere karşı koyabilecek mekanik özelliklere sahip olması gerekmektedir [1-4].

X65 çeliklerinin kimyasal ve mekanik şartnameleri API 5L standardına göre belirlenmiştir. API 5L X65 çelikleri, büyük çaplı gaz boru hatlarının yapım işlerinde kullanılan yüksek mukavemetli ve düşük alaşımlı çelik (HSLA) serilerinden biridir [5]. Bu çelikler, boru hatları için tercih edilen ve ince taneli asiküler ferritin hâkim olduğu, kontrollü termomekanik haddeleme yöntemi ile üretilen karbon çelikleridir [6-8]. Karbon çelikleri doğalgaz ve petrol ürünlerinin taşındığı boru hattı sistemlerinde yoğun olarak kullanılmaktadır. Bu çelikler mühendislik uygulamaları için önemli ölçüde ekonomik özellikleri ile düşük maliyet, kolay elde edilebilirlik ve yüksek mekanik özelliklere sahip olması nedeniyle günümüzde yaygın olarak kullanılmaktadır [9-11]. API çeliklerinin üretiminde kullanılan termomekanik haddeleme; dinamik toparlanma ve yeniden kristalleşme adı altındaki iki farklı yumuşatma mekanizması ile gerçekleşmekte olup, çeliklerin mikro yapı dönüşümleri ve mekanik özelliklerini kontrol etmek için haddeleme esnasında ve sonrasında sicak deformasyon uygulanmaktadır $[12,13]$.

Doğalgaz boru hatları için üretilen borular genellikle tozaltı kaynak yöntemi ile üretilmekte olup, boruların sahada birleştirme işlemleri ise örtülü elektrodla elektrik ark kaynak yöntemi ile gerçekleşmektedir. Son zamanlarda, yapım işi imalat sürecini hızlandırarak, enerji, maliyet ve zamandan tasarruf etmek için sahada yapılan birleştirme işlemlerinde gazaltı kaynak yöntemleri de denenmektedir [14]. Örtülü elektrodla ark kaynağı manuel bir kaynak yöntemi olup, prosesin performans ve başarısı tamamen optimum kaynak parametrelerinin tercih edilmesine ve kaynakçının maharetine bağlıdır. Gazaltı kaynak yöntemleri tel besleme hizı ve kesintisiz kaynak yapabilme özelliği nedeniyle sanayi uygulamalarında yoğun olarak kullanılan bir yöntemdir. Ayrıca kaynak işlemlerinde otomasyon sürecine geçiş noktasında gazaltı kaynağı önemli bir yer tutmaktadır. Otomatik gazaltı kaynağının uygulandığı robotik uygulamalarda son zamanlarda giderek artmaktadır. Otomatik gazaltı kaynağı doğalgaz ve petrol boru hatlarının kaynaklı birleştirme işlemlerinde son zamanlarda denenmekte olup, kullanımı her geçen gün daha da yaygınlaşmaktadır [15].

$\mathrm{Bu}$ çalışmada; Ereğli Demir ve Çelik Fabrikaları T.A.Ş. (Erdemir) tarafindan doğalgaz boru hatlarında kullanılmak üzere üretilen API 5L standardında, X65 kalitesinde çelik malzemeler MAG kaynak yöntemi ile birleştirilmiştir. Elde edilen birleştirmelerden alınan numunelere mikrosertlik, çekme, çentik - darbe ve eğme testleri uygulanmıştır. Ayrıca, kaynaklı birleştirmelerin makro ve mikroyapı fotoğrafları çekilerek, kaynak işleminin mikroyapı ve mekanik özellikler üzerine etkileri incelenmiştir.

\section{MATERYAL VE METOT}

\subsection{Materyal}

Bu çalışmada, sürekli döküm yolu ile imal edilmiş, termomekanik haddelemeye tabi tutulmuş, hidrojen kırılganlığına karşı yüksek dirençli API 5L standartlarında, X65 kalitesinde ve $16 \mathrm{~mm}$ kesit kalınlığında çelik kullanılmıştır. Deneylerde kullanılan API5L X65 malzemesine ait kimyasal analiz ve mekanik test sonuçları Çizelge 1'de verilmiştir. İlave tel olarak, Çizelge 2'de kimyasal ve mekanik özellikleri verilen $1,2 \mathrm{~mm}$ çapında E71T-1 özlü rutil tel kullanılmıştır. Koruyucu gaz atmosferi ise EN439 standardinda M21 koduyla belirtilen \%86 Argon, \%12 $\mathrm{CO}_{2}$ ve \%2 $\mathrm{O}_{2}$ içeriğine sahip, karışım gaz olarak belirlenmiştir. 
Çizelge 1. API 5L X65 malzeme kimyasal kompozisyonu ve mekanik özellikleri

\begin{tabular}{|c|c|c|c|c|c|}
\hline C & Si & Mn & P & S & $\begin{array}{c}\text { Karbon } \\
\text { Eşd. } \\
(\%)\end{array}$ \\
\hline 0,12 & 0,45 & 1,6 & 0,03 & 0,02 & 0,43 \\
\hline $\begin{array}{c}\text { Ak. Muk. } \\
\text { MPa }\end{array}$ & $\begin{array}{c}\text { Çek. Muk. } \\
\text { MPa }\end{array}$ & $\begin{array}{c}\text { Akma / } \\
\text { Çekme } \\
\text { Muk. Oranı }\end{array}$ & $\begin{array}{c}\text { \% } \\
\text { Uzama } \\
(\mathbf{m i n})\end{array}$ & $\begin{array}{c}\text { Dar. } \\
\text { Ener. } \\
\left(\begin{array}{l}\text { Joule) } \\
\left(-20^{\circ} \mathbf{C}\right)\end{array}\right.\end{array}$ \\
\hline $450-600$ & $535-760$ & 0,93 & 24 & 54 \\
\hline
\end{tabular}

Çizelge 2.E71T-1 ilave telin kimyasal kompozisyonu ve mekanik özellikleri

\begin{tabular}{|c|c|c|c|}
\hline İlave Tel & $\mathbf{C}$ & $\mathbf{S i}$ & $\mathbf{M n}$ \\
\hline E71T-1 & $0,04-0,08$ & $0,03-0,07$ & $1,10-1,5$ \\
\hline $\begin{array}{c}\text { Akma } \\
\text { Dayanımı } \\
\text { MPa }\end{array}$ & $\begin{array}{c}\text { Çekme } \\
\text { Dayanımı } \\
\text { MPa }\end{array}$ & $\begin{array}{c}\text { \% } \\
\text { Uzama } \\
(\mathbf{m i n})\end{array}$ & $\begin{array}{c}\text { Darbe } \\
\text { Enerjisi } \\
(\mathbf{J o u l e}) \\
(\mathbf{- 2 0} \mathbf{C})\end{array}$ \\
\hline 450 & $540-640$ & 22 & 54 \\
\hline
\end{tabular}

\subsection{Metot}

Birleştirme işlemleri 6 pasoda gerçekleştirilmiş olup, kaynak ağzı geometrisi ve paso sıralaması sırasıyla Şekil 1. a ve b'de görüldüğü gibidir. Birleştirmeler, Emek Boru Mak. San. ve Tic. A.Ş’nin Ankara'daki Fabrikasında Çizelge 3'teki kaynak parametrelerine göre, MAG kaynak yöntemi ile doğru akımda (DC) ve pozitif kutuplamada $1 \mathrm{G}$ pozisyonunda birleştirilmiştir. Kaynak işleminden önce malzemelere $80^{\circ} \mathrm{C}$ 'de önısıtma işlemi gerçekleştirilmiş, pasolar arası sıcaklık ise maksimum $200^{\circ} \mathrm{C}$ 'de tutulmuştur.

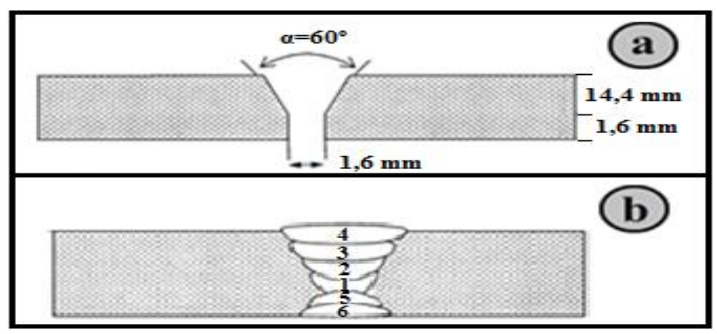

Şekil 1. a) Kaynak ağzı geometrisi, b) Kaynak pasolar1
Çizelge 3. Deneylerde kullanılan kaynak parametreleri

\begin{tabular}{|c|c|c|c|}
\hline $\begin{array}{c}\text { Paso } \\
\text { No }\end{array}$ & $\begin{array}{c}\text { Akım } \\
\text { Şiddeti (A) }\end{array}$ & $\begin{array}{c}\text { Gerilim } \\
\text { (V) }\end{array}$ & $\begin{array}{c}\text { Kaynak Hızı } \\
\text { (cm/dak) }\end{array}$ \\
\hline $\mathbf{1}$ & $190-200$ & $26-27$ & 10,6 \\
\hline $\mathbf{2}$ & $240-250$ & $27-28$ & 8,5 \\
\hline $\mathbf{3}$ & $300-310$ & $32-33$ & 8,6 \\
\hline $\mathbf{4}$ & $225-235$ & $28-29$ & 10,3 \\
\hline $\mathbf{5}$ & $230-240$ & $27-28$ & 19,8 \\
\hline $\mathbf{6}$ & $220-230$ & $28-29$ & 15,6 \\
\hline
\end{tabular}

Çizelge 3'te verilen kaynak parametrelerine uygun olarak birleştirilen parçalardan çekme, çentik darbe ve eğme deneyleri için 5'er adet numune alınarak, testler uygulanmış, ayrıca mikroyapı numunesinden mikro ve makro yap1 fotoğrafları alınarak, numunelere mikrosertlik testleri uygulanmıştır. Makroyapı, mikroyapı ve mikrosertlik incelemeleri Gazi Üniversitesi Teknoloji Fakültesi Metalurji ve Malzeme Mühendisliği Laboratuvarlarında, çekme, çentik darbe, eğme testleri ise Emek Boru Makine San. ve Tic. A.Ş. Laboratuvarlarında gerçekleştirilmiştir.

Makroyapı - mikroyapı incelemeleri ve mikrosertlik ölçümleri için numuneler, metalografik metotlara uygun olarak hazırlanmıştır. Numuneler sırasıyla; 200, 400, 600, 800,1000 ve 1200 gridlik zımparalama işlemine tabi tutulmuş, 6 ve $3 \mu$ m'lik keçelerde parlatılmıştır. Parlatılan numuneler, daha sonra \%3 HNO3 (Nital) dağlayıcı ile dağlanarak makro ve mikro incelemelere hazır hale getirilmiştir. Numunelerin mikroyapı fotoğrafları için Leica marka optik mikroskop kullanılmıştır. Mikrosertlik ölçümleri ise, makro ve mikro ölçümler yapılabilen, Shimadzu marka sertlik cihazında 0,5 ve $1 \mathrm{~kg}$ yükler kullanılarak gerçekleştirilmiştir.

ASTM E8 standardına uygun olarak hazırlanan çekme numuneleri $600 \mathrm{KN}$ yük kapasitesine sahip Instron marka çekme cihazında test edilmiştir. Deneylerde maksimum çekme mukavemeti ve \% uzama değerlerine bakılarak, ortalama değerler belirlenmiştir. Eğme testleri ise yine aynı cihazda $40 \mathrm{~mm}$ çapında mil (mandrel) ile 63,2 mm kalıp mesafesinde ve $180^{\circ}$ açıda kök bükme (root) ve yüzey bükme (face) olarak gerçekleştirilmiştir. 
API 5L X65 Çeliklerinin MAG Kaynak Yöntemi ile Birleştirilmesinde, Kaynak Işsleminin Mikroyapı ve Mekanik Özelliklere Etkisinin Incelenmesi

Çentik - darbe deneyleri ise maksimum 300 Joule enerji ölçebilen ve çarpma hızı $5,42 \mathrm{~m} / \mathrm{sn}$ olan bir cihaz yardımı ile yapılmıştır. Numuneler EN 10045 standardına göre sivri çentikli ISO-V şeklinde testler için hazırlanmıştır. Numune soğutması, sıvı azot banyosu içinde $\pm 0,5{ }^{\circ} \mathrm{C}$ hassasiyet ile yapılmış olup, numunelerin banyo içinde tutulma süresi 7 dakikadır. Çentik - darbe deneyleri, $\quad-20 \quad{ }^{\circ} \mathrm{C}$ 'de gerçekleştirilmiş olup, numuneler cihaza çentik ekseni mesnet açıklığının tam ortasında ve çentikli yüz, çekicin vuracağı yüzün ters tarafinda olacak şekilde yapılmıştır.

\section{BULGULAR VE TARTIŞMA}

Metalografik numune hazırlama metotlarına uygun olarak hazırlanan mikroyapı numunesi; makroyapı, mikroyapı ve mikrosertlik incelemelerine tabi tutulmuştur. Şekil 2'de kaynaklı birleştirmeden alınan numunenin makroyapı fotoğrafı görülmektedir. Makroyapı fotoğrafi incelendiğinde, ana malzeme, ITAB ve kaynak metalinin birbirinden ayrıldığı bölgeler açıkça görülebilmektedir. 6 pasoda gerçekleşen kaynaklı birleştirme işleminde (Şekil 1.b), paso geçişleri de makroyapı fotoğrafında açıkça görülebilmektedir. İlave metal ile birlikte ana metalden ergiyerek kopan taneler yoğun türbülansın da etkisiyle birlikte katılaşarak, kaynak metali yapısını oluşturmuştur. Kaynak metalindeki katılaşmanın epitaksiyel olarak ana metalin tanelerinden başlayarak merkeze doğru ilerlediği bilinmektedir [16-18]. Isının tesiri altındaki bölge katılaşmanın başladığı çizgiden ana metale kadar uzanan ve yapısal farklılıkların makro olarak da görülebildiği bir yapıdır. Ana metal ve kaynak metali arasında kalan, ergime - katılaşma olmadan yüksek 1sı etkisi ile yapısal olarak değişime uğrayan bölge ise, ısının tesiri altındaki bölge (ITAB) olarak Şekil 2'de görülmektedir [16-19]. Maruz kaldığ1 1S1 miktarına göre ITAB içerisinde de yapısal farklılıklar oluşmaktadır. Kaynak metali sınırında koyu renkte görülen ITAB makroyapısının, ana metale yaklaştıkça daha açık renkte olduğu görülmektedir. Mikroyapı incelemelerinde oluşan bu yapısal farklılıklar açıkça görülmektedir (Şekil 3.a).

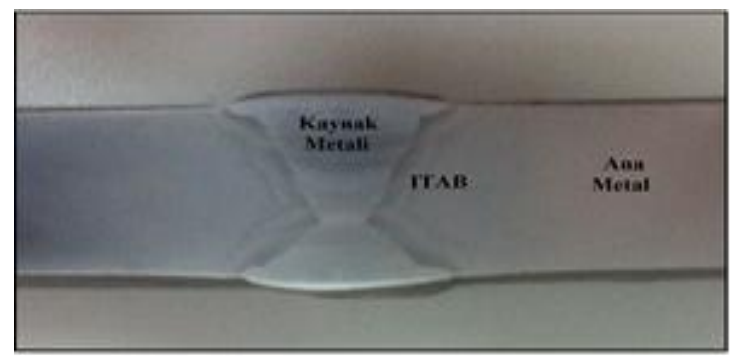

Şekil 2. X65 malzeme makroyapı fotoğrafı

Şekil 3'te ise mikroyapı görüntüleri ayrıntılı olarak verilmektedir. Şekil 3.a'da $100 \mu$ m'de ölçeklendirilmiş mikroyapı fotoğrafında ana metal, ITAB ve kaynak metali mikroyapısını birlikte görülmektedir. Şekil 3.b'de ana metal, Şekil 3.c'de ITAB ve Şekil 3.d'de ise kaynak metali mikroyapısı $20 \mu \mathrm{m}$ olarak ölçekli fotoğraflar verilmiştir.

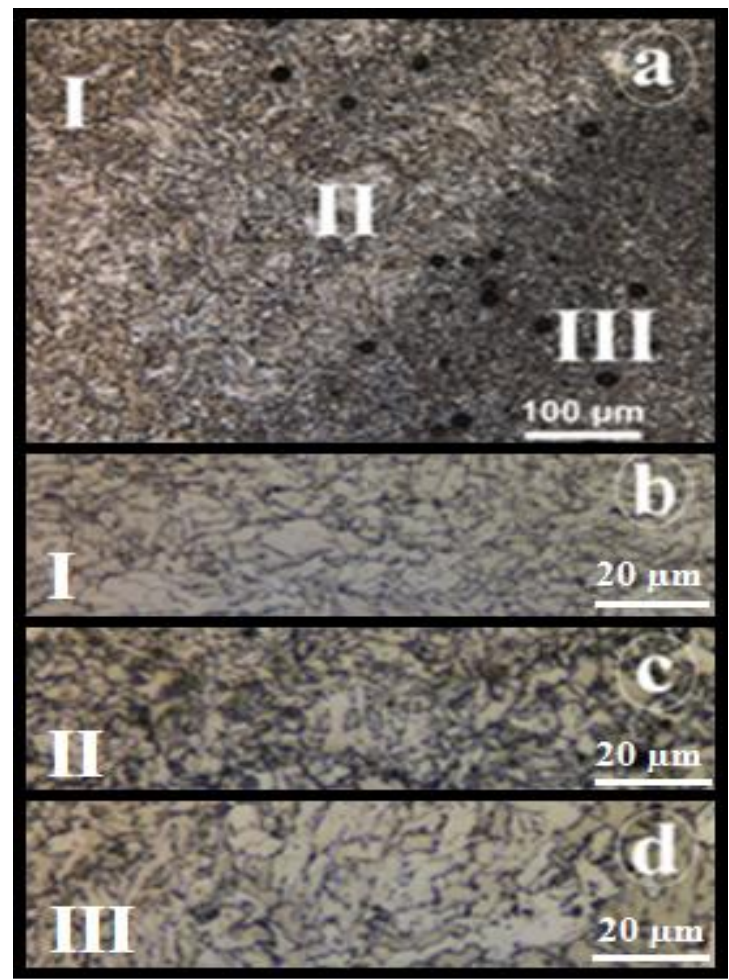

Şekil 3. a) Kaynak metali - ITAB - Ana metal mikroyap1 görüntüsü, b) Ana metal mikroyap1 görüntüsü, c) ITAB mikroyap1 görüntüsü, d) Kaynak metali mikroyapı görüntüsü 
Şekil 3.a'da verilen mikroyapı fotoğrafinda, tipik ana metal, ITAB ve kaynak metali mikroyapısı bir arada görülmektedir. Fotoğraf üzerinde, I, II ve III numara ile numaralandırılan bölgeler sırasıyla; ana metal, ITAB ve kaynak metali bölgelerini göstermektedir. I ve III numara ile gösterilen bölgelerde ana metal ve kaynak metali tanelerinin homojen dağılımlı tane yapısında oluştuğu görülmektedir [20]. Ana metal tanelerinde daha iri taneli yapılar oluşurken, kaynak işleminde aşırı ısınma ve hızlı soğuma etkilerine bağlı olarak oluşan asiküler ferrit tanelerinin yoğunluğu nedeniyle, kaynak metali içerisinde daha ince taneli yapının oluştuğu görülebilmektedir [21, 22]. ITAB'da ise 1 sının etkisi ile ana metal ve kaynak metalinde oluşan yapılardan daha farklı yapıların oluştuğu gözlemlenmektedir. $\mathrm{Bu}$ durum Şekil 3.a'da verilen II numaralı bölgede açıkça görülmektedir. $\mathrm{Bu}$ bölgedeki ITAB yapısında tanelerin, ana metal yönünden kaynak metali yönüne doğru dendritik olarak uzadığı görülmektedir. Dendritik yapının hâkim olduğu ITAB tane yapısı içerisinde yer yer iğnemsi widmanstatten yapının oluştuğu da tespit edilmiştir [23]. Yine kaynak metali içerisinde sütunsal ferrit tanelerinin yoğun olarak bulunduğu görülmektedir. $\mathrm{Bu}$ duruma, paso sayısının artmasıyla birlikte 1S1 girdisinde meydana gelen artışın neden olabileceği düşünülmektedir [24].

Çizelge 4'teki çekme deney verileri incelendiğinde, bütün numunelerde kopmanın ana malzeme meydana geldiği, kaynaklı bölgede kopmanın olmadığı tespit edilmiştir. Bu sonuç; uygulanan kaynak işleminin mekanik yüklemelerdeki dayanımının kaynak metalinde, ana malzemeye göre daha iyi tavırlar sergilediğini göstermektedir. Buna sebep olarak kaynaklı bölgede yüksek 1Sı girdisi ve hızlı soğumadan kaynaklanan ince taneli ve iğnemsi yapıların oluşması gösterilebilir. Oluşan ince taneli yapıların mekanik özellikleri olumlu yönde etkilediği bilinmektedir [25]. İnce taneli yapıların deformasyona karşı gösterdiği direnç yüksek olduğu için kopma kaynak metalinde gerçekleşmeyip, daha iri tane yapısına sahip olan ana metalde meydana gelmiştir. Kaynaklı bölgenin çekme testi esnasında deformasyona karşı gösterdiği direnç, çekme numunelerinin \% uzama değerlerinin ana malzemeye oranla daha düşük çıkmasına neden olmakta ve bu nedenle kopma ana malzemede oluşmaktadır. Buna paralel olarak çekme mukavemetinin artması yine kaynaklı bölgenin deformasyona karşı gösterdiği direnç nedeniyledir [25,26].

Çizelge 4. Çekme testi sonuçları

\begin{tabular}{|c|c|c|c|}
\hline Numune & $\begin{array}{c}\text { Maksimum } \\
\text { Çekme } \\
\text { Dayanımı } \\
\left(\mathbf{N} / \mathbf{m m}^{\mathbf{2}}\right)\end{array}$ & $\begin{array}{c}\text { \% } \\
\text { Uzama }\end{array}$ & Kırılma Bölgesi \\
\hline $\mathbf{1}$ & 590 & 26 & Ana malzeme \\
\hline $\mathbf{2}$ & 587 & 27 & Ana malzeme \\
\hline $\mathbf{3}$ & 601 & 22 & Ana malzeme \\
\hline $\mathbf{4}$ & 595 & 24 & Ana malzeme \\
\hline $\mathbf{5}$ & 603 & 22 & Ana malzeme \\
\hline Ortalama & 595 & 24 & Ana Malzeme \\
\hline
\end{tabular}

Çekme testi sonuçları incelendiğinde en yüksek maksimum çekme mukavemeti değerinin $603 \mathrm{MPa}$ ile 5 numaralı numunede olduğu görülürken, en düşük maksimum çekme mukavemetinin ise $587 \mathrm{MPa}$ ile 2 numaralı numunede olduğu tespit edilmiştir. 3 ve 5 numaralı numunelerde $\% 22$ ile en düşük \% uzama değerleri görülürken, en yüksek değer \%27 uzama ile 2 nolu numunede görülmektedir. Ortalama değerler ise maksimum çekme mukavemeti için $595 \mathrm{MPa}$ \% \% uzama değeri için ise \%24'tür.

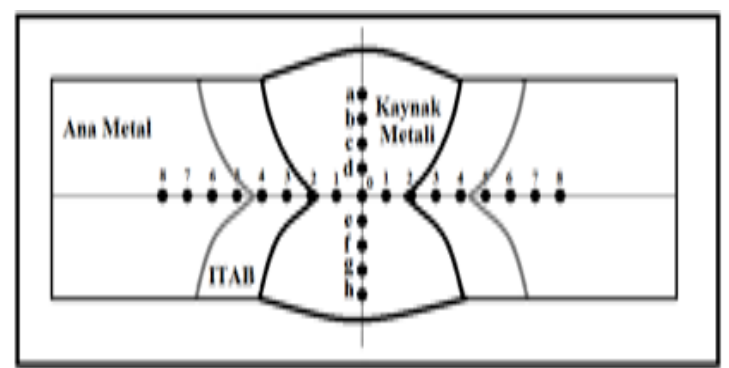

Şekil 4. Sertlik alınan bölgelerin şematik gösterimi

Sertlik ölçümleri ise Şekil 4'te şematik olarak gösterilen noktalardan alınmıştır. Enine 17 noktadan alınan sertlik ölçümleri kaynak işlemi sonucunda oluşan farklı mikroyapıların (ana metal, ITAB, kaynak metali) sertlik davranışını tespit etmek için yapılmıştır. Kaynak metali içerisinde 9 farklı noktadan boyuna alınan sertlik ölçümleri ise, kaynak pasolarının kaynak metali sertliği üzerine 
etkilerini tespit etmek için yapılmıştır. Sertlik sonuçları Şekil 5'te verilen grafikteki gibidir.

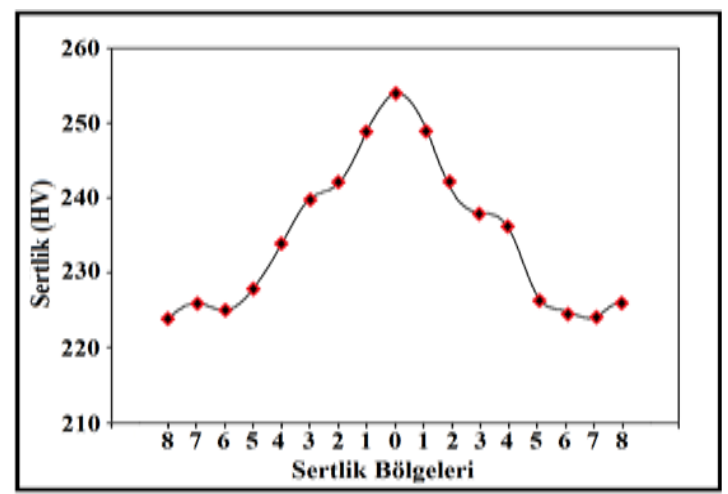

Şekil 5. Sertlik grafiği

Sertlik sonuçları irdelendiğinde en yüksek sertlik değerlerinin kaynak metalinde ölçüldüğü görülürken, en düşük değerler ise ana malzemede ölçülmüștür (Şekil 5). En yüksek sertlik değerlerinin kaynak metalinde oluşmasına, yüksek 1S1 girdisi ve hızlı soğuma neticesinde oluşan ince taneli yapıların sebep olduğu düşünülmektedir. Mikroyapı fotoğrafları incelendiğinde kaynak metalinde ince taneli ve benzer yapıların varlığ 1 dikkat çekmektedir (Şekil 5). Tüm kaynak bölgelerinin enine incelendiği ölçümlerde en yüksek sertlik değeri kaynak metalinde 0 noktasında $254 \mathrm{HV}$ olarak ölçülmüsşür. En düşük değerler ise ana malzemede, 6,7 ve 8 numara ile belirtilen noktalarda yaklaşık 225 HV olarak ölçülmüştür. Yapılan çalışmalarda benzer sertlik sonuçları elde edilmesi yapılan çalışmanın doğruluğunu göstermektedir [27-31].

Çizelge 5. Kaynak metali boyuna sertlik ölçümleri

\begin{tabular}{|l|c|c|c|c|c|}
\hline Bölge & a & b & c & d & 0 \\
\hline HV & 257 & 247 & 237 & 243 & 254 \\
\hline Bölge & e & f & g & h & Ort. \\
\hline HV & 261 & 232 & 250 & 235 & $\mathbf{2 4 6}$ \\
\hline
\end{tabular}

Kaynak bölgesinden boyuna alınan sertlik ölçümlerinde ise Çizelge 5'te verilen sonuçlara ulaşılmıştır. Sonuçlar incelendiğinde; kaynak metali sertliğinde, ana malzeme sertlik sonuçlarına oranla daha yüksek sertlik değerlerine ulaşıldığ 1 görülmüştür. En yüksek sertlik değeri 261 HV ile e noktasında tespit edilirken, en düşük sertlik değeri $232 \mathrm{HV}$ ile f noktasında elde edilmiştir. Boyuna alınan sertlik ölçümlerindeki sonuçların farklılık göstermesi, kaynak işleminin çok pasoda gerçekleştirilmesine bağlanmaktadır. Ergime ve katılaşmanın birden fazla gerçekleştiği, çok pasolu kaynak işlemleri, yüksek 1sı girdisine ve soğuma hızlarına sebep olduğu için kaynak metali tane yapısının kontrollü ve homojen olarak oluşmasını engellemiştir. $\mathrm{Bu}$ nedenle boyuna alınan sertlik sonuçlarında farklı sertlik değerlerine ulaşılmıştır [32].

Kaynak metalinden alınan numunelere, $-20{ }^{\circ} \mathrm{C}$ 'de yapılan çentik - darbe deneylerinde Çizelge 6'da verilen değerler tespit edilmiştir. Sonuçlar incelendiğinde en yüksek kırılma tokluğu 68 Joule ile 3 nolu numunede görülürken, en düşük ölçüm 63 Joule ile 1 numaralı numunede olduğu görülmüştür. Çentik darbe sonuçlarının ortalaması alındığında ise 66 Joule'lük bir darbe enerjisi elde edilmiştir.

Çizelge 6. Kaynak metali sertlik sonuçları

\begin{tabular}{|c|c|}
\hline Numune & $\begin{array}{c}\text { Enerji (Joule) } \\
\text { Test sicaklığı: }-20\end{array}{ }^{\circ} \mathbf{C}$ \\
\hline $\mathbf{1}$ & 63 \\
\hline $\mathbf{2}$ & 66 \\
\hline $\mathbf{3}$ & 68 \\
\hline $\mathbf{4}$ & 65 \\
\hline $\mathbf{5}$ & 67 \\
\hline Ortalama & $\mathbf{6 6}$ \\
\hline
\end{tabular}

Eğme deneyleri; kaynaklı malzemelerde makro olarak bir hatanın oluşup oluşmadığını görmek için Çizelge 7'de verilen mandrel çapı ve kalıp mesafesinde kaynağın her iki yönüne (kök ve yüzey) uygulanmıştır. $180^{\circ}$ açıda uygulanan eğme deneylerinde, malzemelerde çatlama, yırtılma v.b. hataların oluşmadığı görülmüş̧tür (Çizelge 7).

Çizelge 7. Eğme testi parametreleri ve sonuçları

\begin{tabular}{|c|c|c|c|c|c|}
\hline \multirow{2}{*}{$\begin{array}{c}\text { Mandrel } \\
\text { Çapı } \\
(\mathbf{m m})\end{array}$} & \multirow{2}{*}{$\begin{array}{c}\text { Kalıp } \\
\text { Mesafesi } \\
(\mathbf{m m})\end{array}$} & \multicolumn{2}{|c|}{ Kök Bükme } & \multicolumn{2}{|c|}{$\begin{array}{c}\text { Yüzey } \\
\text { Bükme }\end{array}$} \\
\cline { 3 - 6 } & & Açı & Sonuç & Açı & Sonuç \\
\hline 40 & 63,2 & $180^{\circ}$ & $\begin{array}{c}\text { Hata } \\
\text { yok }\end{array}$ & $180^{\circ}$ & $\begin{array}{c}\text { Hata } \\
\text { yok }\end{array}$ \\
\hline
\end{tabular}


Eğme testi sonuçları birleştirme işleminin uygun bir şekilde yapıldığını göstermektedir. Şekil 6'da eğme deneyi uygulanmış bir numunenin görüntüsü verilmektedir.

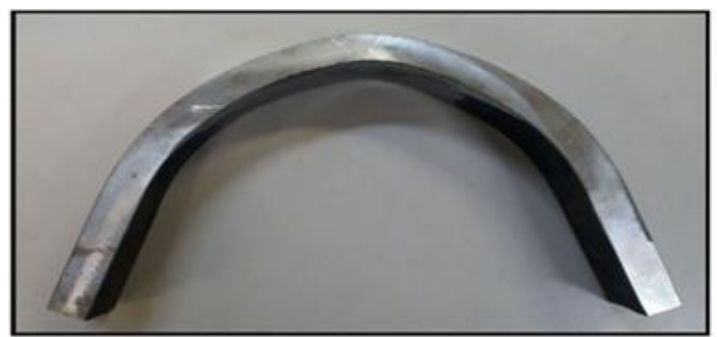

Şekil 6. Eğme testi uygulanmış numune

\section{SONUÇLAR}

- İlave metal ile birlikte ana metalden ergiyerek kopan taneler yoğun türbülansın da etkisiyle birlikte katılaşarak, kaynak metali yapısını oluşturmuştur.

- Maruz kaldığı 1sı miktarına göre ITAB içerisinde de yapısal farklılıklar oluşmuştur. Kaynak metali sınırında koyu renkte görülen ITAB makroyapısının, ana metale yaklaştıkça daha açık renkte olduğu görülmüştür.

- Kaynak metali ve ana malzeme mikroyapısının homojen dağılımlı tane yapısında oluştuğu tespit edilmiştir.

- Ana metal tanelerinde daha iri taneli yapılar oluşurken, kaynak işleminde aşırı ısınma ve hızlı soğuma etkilerine bağlı olarak oluşan asiküler ferrit tanelerinin yoğunluğu nedeniyle, kaynak metali içerisinde daha ince taneli yapının oluştuğu görülmüştür.

- Isının tesiri altındaki bölgede tanelerin, ana metal yönünden kaynak metali yönüne doğru dendritik olarak uzadığg ve yer yer iğnemsi widmanstatten yapının oluştuğu tespit edilmiştir.

- İnce yapilı kaynak metali tanelerinin deformasyonu engellemesi nedeniyle kopma, tüm numunelerde ana malzemelerde meydana gelmiş, kaynaklı bölgelerden herhangi bir kopmanın olmadığı tespit edilmiştir. Bu durum kaynak işleminin doğru yapıldığını göstermiştir.
- Sertlik sonuçları irdelendiğinde en yüksek sertlik değerlerinin kaynak metalinde ölçüldüğü görülürken, en düşük değerler ise ana malzemede ölçülmüştür. $\mathrm{Bu}$ durum uygulanan kaynak işleminin uygun performansta olduğunu desteklemiştir.

- Boyuna alınan ölçümlerde sertlik sonuçlarının farklı1ık göstermesi, kaynak işleminin çok pasoda gerçekleştirilmesinden kaynaklanmıştır.

- Mekanik test sonuçları, birleştirme işleminin uygun bir şekilde yapıldığını göstermiştir.

\section{KAYNAKLAR}

1. Bai, Y., 2001. Pipelines and Risers, Elsevier, Oxford, UK.

2. Baek, J. H., Kim, Y. P., Kim, K., Kim, C.M., Kim, W.S. and Seok, C. S., 2010. Effects of Pre-strain on the Mechanical Properties of API 5L X65 Pipe, Materials Science and Engineering (A), 527, p. 1473-1479.

3. Baek, J., Kima, Y., Kima, W.,Koo, J., Seok, C, 2012. Load bearing capacity of API X65 pipe with dent defect under internal pressure and inplane bending, Materials Science and Engineering (A) 540, p. 70-82.

4. Cosham, A., Hopkins, P., 2004. The effect of dents in pipelines - guidance in the pipeline defect assessment manual, International Journal of Pressure Vessels and Piping, $81 \mathrm{pp}$. $127-139$.

5. API Specifications 5L, 2007. Specificationsfor Line Pipe, 44th Edition, American Petroleum Institute, USA.

6. Hashemi, S.H., 2011. Strength - hardness statisticalcorrellation in API X65 steel, Material Science and Engineering (A) 528, pp. 1648-1655.

7. Hashemi, S.H., Mohammadyani, D., 2012. Characterisation of weldment hardness, impactenergy and microstructure in API X65 steel, International Journal of Pressure Vessels and Piping, 98, pp. 8-15.

8. Rakhshkhorshid, M., Hashemi, S.H., 2013. Experimental study of hot deformation behavior in API X65 steel, Materials Science and Engineering (A) 573, pp. 37-44.

9. Ada, H. 2006. Petrol ve doğalgaz boru hatları için üretilen boruların tozaltı ve spiral kaynak 
yöntemiyle kaynaklanabilirliği ve mekanik özelliklerinin incelenmesi, Yüksek Lisans Tezi, Gazi Üniversitesi.

10. Migahed, M.A., Al-Sabagh, A.M., Khamis, E.A., Zaki, E.G., 2015. Quantum Chemical calculations, synthesis and corrosion inhibition efficiency of ethoxylated-[2-(2-\{2-[2-(2benzene sulfonyl amino ethylamino) ethylamino] -ethylamino - ethylamino - ethyl] - 4 - alkyl benzene sulfonamide on API X65 steel surface under H2S environment, Journal of Molecular Liquids, 212, pp. 360-371.

11. Rani, B.E., Amitha. and Basu, Bharathibai, J., 2009. Green corrosion inhibitors - an overview, Technical Report, National Aerospace Laboratories, Bangalore, India.

12. Shaban, M., Eghbali, B., 2010. Determination of critical conditions for dynamic recrystallization of a microalloyed steel, Materials Science and Engineering (A), 527, pp. 4320-4325.

13. Jin, W., Jun, C., Zhen, Z., Xue-yu, R.J., 2008. Iron Steel Res. Int. 15, pp. 78-81.

14. Moradpour, M.A., Hashemi, S.H., Khalili, K., 2015. Multi - objective Optimization of Welding Parameters in Submerged Arc Welding of API X65 Steel Plates, Journal of Iron and Steel Research, 22, pp. 870-878.

15. Kirkwood, P.R., Prosser, K., Boothby, P.J., 1984. The Properties of Pipeline Girth Weld Produced by Arcwelding Process, Welding in Energy RelatedProjects, pp. 359-377.

16. Keehan, E., 2004. Effect of Microstructure on Mechanical Properties of High Strength Steel Weld Metals Department of Experimental Physics, Göteborg University, pp. 1-72.

17. Ada, H., Aksöz, S., Fındık, T., Çetinkaya, C., Gülsün, M., 2016. Investigation of Microstructure and Mechanic Properties of Petroleum and Natural Gas Pipeline Weldment by Submerged Welding Processes, Journal of Polytechnic, 19 (3) : 275-282.

18. Ada H., Aksöz, S., Özer, A., Candan, İ., 2016. Investigation of Metallurgical and Mechanical Properties of Welded Region of API 5L X80 Steel Merged by Submerged Arc Welding Method, ICAT 2016 International Conference on Advances Technology and Science, Konya,309.
19. Aucott, L.A., Wen, S.W., Dong, H. 2015. The role of $\mathrm{Ti}$ carbo nitride precipitates on fusion zone strength - toughness in submerged arc welded pipeline joints, Materials Science and Engineering (A), 622, pp. 194-203.

20. Ju, J.B., Kim, W., Jang, J., 2012. Variations in DBTT and CTOD with in weld heat affected zone of API X65 pipeline steel, Materials Science and Engineering (A), 546, pp. 258262.

21. Shanmugam, S., Misra, R.D.K., Hartmann, J., Jansto, S.G., 2006. Microstructure of high strength niobium containing pipeline steel, Materials Science and Engineering (A), 441, pp. 215-229,

22. Hashemi, S.H., Mohammadyani, D. 2012. Characterisation of weldment hardness, impactenergy and microstructure in API X65 steel, International Journal of Pressure Vessels and Piping, 98, pp. 8-15.

23. Easterling, K., 1992. Introduction to the physical metallurgy of welding, ButterworthHeinemann; England.

24. Sulea, J., Gangulya, S., Coules, H., Pirling, T., 2015. Application of local mechanical tensioning and laser processing to refine microstructure and modify residual stres state of a multi - pass 304L austenitic steels welds, Journal of Manufacturing Processes, 18, pp. 141-150.

25. Lehto, P., Remes, H., Saukkonen, T., Hänninen, H., Romanoff, J., 2014. Influence of grain size distribution on the Hall-Petch relationship of welded structural steel, Materials Science and Engineering (A), 592, pp. 28-39.

26. Kahraman, N., Gülenç, B., Durgutlu, A., 2005. Tozaltı ark kaynağı ile kaynaklanan düşük karbonlu çeliklerde serbest tel uzunluğunun mikroyapı ve mekanik özelliklere olan etkisinin araştırılması, Gazi Üniversitesi Fen Bilimleri Dergisi, 18 (3), 473-480.

27. Eroğlu, M., Aksoy, M., 2002. 15Mo3 Çeliğinin Kaynağında Enerji Girişinin Kaynak Bölgesinin Mikroyapısı ve Mekanik Özelliklerine Etkisi, Kaynak Teknolojisi 2. Ulusal Kongresi, 38.

28. Pouralıakbar, H., Khalaj, M., Nazerfakhari, M., Khalaj, G., 2015. Artificial Neural Networks 
for Hardness Prediction of HAZ with Chemical Composition and Tensile Test of X70 Pipeline Steels, Journal of Iron and Steel Research, 22-5, pp. 446-450.

29. Ada, H., Aksöz, S., Özer, A., 2016. Investigation of Metallurgical and Mechanical Properties of Welded Region of API 5L X80 Steel Merged by Gas Metal Arc Welding Method, International Multidisciplinary Congres of Eurasia 216, 11st-13th July, Ukraine, 2: 156 - 162.

30. Özer, A., Aksöz, S., Ada, H., Candan, İ., 2016. Investigation of Metallurgical and Mechanical Properties of Welded Region of API 5L X80 Steel Merged by Electric Arc Welding Method, International Multidisciplinary Congres of Eurasia 216, 11st-13th July, Ukraine, 2: 354360.

31. Aksöz, S., Ada, H., Fındık, T., Çetinkaya, C., Bostan B., Candan, İ. 2016. The Investigation of Effect of Welding Process on the Microstructure and Mechanical Properties of API 5L X65 Steel Welded with Electric Arc Welding Method, 4. International Conference on Welding Technologies and Exhibition, 1113 May, Gaziantep, 684-693.

32. Alipooramirabada, H., Paradowska, A., Ghomashchi, R., Kotousova, A., Reid, M., 2015. Quantification of residual stresses in multi - passwelds using neutron diffraction, Journal of Materials Processing Technology, 226, pp. 40-49. 
